Perspectiva Geográfica

ISSN 0123-3769

Vol. 15/2010; pp. 157-176

\title{
Organización espacial de la región geográfica de la Alta Guajira colombiana
}

Spatial organization of the geographic colombian region

of Alta Guajira

Miguel Aponte*

\section{Resumen}

Los desiertos del mundo constituyen espacios de la superficie terrestre donde tienen lugar procesos y dinámicas de funcionamiento muy particulares, producto de las estrechas relaciones que han establecido sus habitantes con el medio natural. Estos territorios son considerados por los ambientalistas como vulnerables al cambio climático global, cuyos efectos son impredecibles en relación con el avance de la desertificación, las migraciones y el aumento de la pobreza. En esta investigación se indaga acerca de la organización espacial del denominado "desierto guajiro", localizado al norte de Suramérica. Se determinan las estructuras (naturales y sociales) que sostienen este territorio y que han permitido el desarrollo y permanencia durante siglos de la cultura wayúu. Se emplea el método de investigación analítico sintético. Los resultados obtenidos constituyen fuente de consulta para el diseño e implementación de políticas de desarrollo socio económico y de conservación ambiental que se ajusten a las características del medio natural y de la sociedad que lo habita.

Palabras clave: Espacio geográfico, Guajira, Organización espacial, Wayúu.

* Magíster en geografía. Profesional especializado, Instituto Geográfico Agustín Codazzi -IGAC-. maponte@igac.gov.co, migueaponte@gmail.com 


\begin{abstract}
The world's deserts are spaces of the Earth's surface where very particular processes and dynamics of operation take place, as a result of the close relationship that their inhabitants have established with the natural environment. These territories are considered by environmentalists as vulnerable to global climate change, whose effects are unpredictable in relation to the advance of desertification, migration and the increase in poverty. This research investigates on the spatial organization of the so called "guajiro desert", located to the North of South America. It identifies the (natural and social) structures that hold this territory and that have allowed the development and permanence during centuries of the Wayuu culture. The analytic synthetic research method is used. The results are a source of consultation for the design and implementation of policies of socio economic development and environmental conservation which conform to the characteristics of the natural environment and the society that inhabits it.
\end{abstract}

Key words: Geographic space, Guajira, Spatial organization, Wayuu. 


\section{Introducción}

Del variado mosaico de ecosistemas terrestres, los desarrollados en zonas secas y muy secas son los de mayor vulnerabilidad al cambio climático, debido a su alta susceptibilidad a las ligeras variaciones en la disponibilidad de agua bajo condiciones naturales; cualquier alteración de ellos podría tener graves consecuencias en la diversidad biológica, en las poblaciones y en las economías (CCC, 1997). Estos ecosistemas han sido agrupados a nivel mundial bajo la denominación genérica de "tierras secas" e incluyen todas las regiones terrestres cuya producción de cultivos, forraje y fibras, y otros servicios de ecosistemas están limitados por el agua (Instituto Mundial sobre Recursos, 2005). Las "tierras secas", a nivel global, cubren aproximadamente las dos quintas partes de la superficie de la Tierra y albergan cerca del $35 \%$ de la población mundial, es decir, unos 2.300 millones de habitantes (PNUMA, 2006). Además de ser vulnerables al cambio climático, son propensas al desarrollo de procesos de desertificación ${ }^{1}$ por causa de la sobreexplotación y el aprovechamiento inadecuado de las tierras.

En las zonas desérticas del mundo habitan diversas culturas que, con sus estilos de vida propios, generan unas estructuras espaciales y una funcionalidad particular de cada espacio geográfico. Para el caso referido a la región geográfica de la Alta Guajira en Colombia, la sociedad Wayúu no es la excepción, pues esta ha organizado su territorio de acuerdo con una espacialidad ${ }^{2}$ propia en función de sus valores, creencias y normas, así como también del conocimiento profundo del entorno natural.

El enfoque de este estudio es eminentemente geográfico y está dirigido a la indagación acerca de la configuración y organización espacial del desierto de la Guajira, como región cultural de características particulares, con miras a aportar elementos de juicio que contribuyan a la planificación y ordenación del territorio bajo criterios de sostenibilidad, no solamente en cuanto al medio natural, sino también respecto a la permanencia e identidad cultural de la sociedad wayúu asentada en este territorio.

\section{Planteamiento del problema de investigación}

Los territorios ubicados en las zonas secas del planeta Tierra (Figura 1) son objeto de fuertes presiones humanas para extraer alimentos, fibras, madera y recursos

Según la lengua española, los verbos "desertificar" y "desertizar" son sinónimos. En el contexto de la presente investigación se utilizará la palabra desertización, a cambio de desertificación (traducción literal del idioma inglés), para significar la expansión de las condiciones desérticas por cualquier razón. El término incluye no solo la erosión, sino también toda degradación del suelo (pérdida de nutrientes, salinización, etc.) que implique un descenso de su productividad. Dos son las causas que generan desertización: el cambio climático y el mal uso del suelo.

2 "La espacialidad reúne el conjunto de condiciones y prácticas de la vida individual y social que están ligadas a la posición relativa (o situación geográfica) de los individuos y los grupos, unos con otros. Las situaciones geográficas determinan, en mayor o menor medida, la forma y la intensidad de las interacciones sociales" (Hypergéo, 2004).

Perspect. geogr. Vol. 15. Año 2010, pp. 157-176 159 


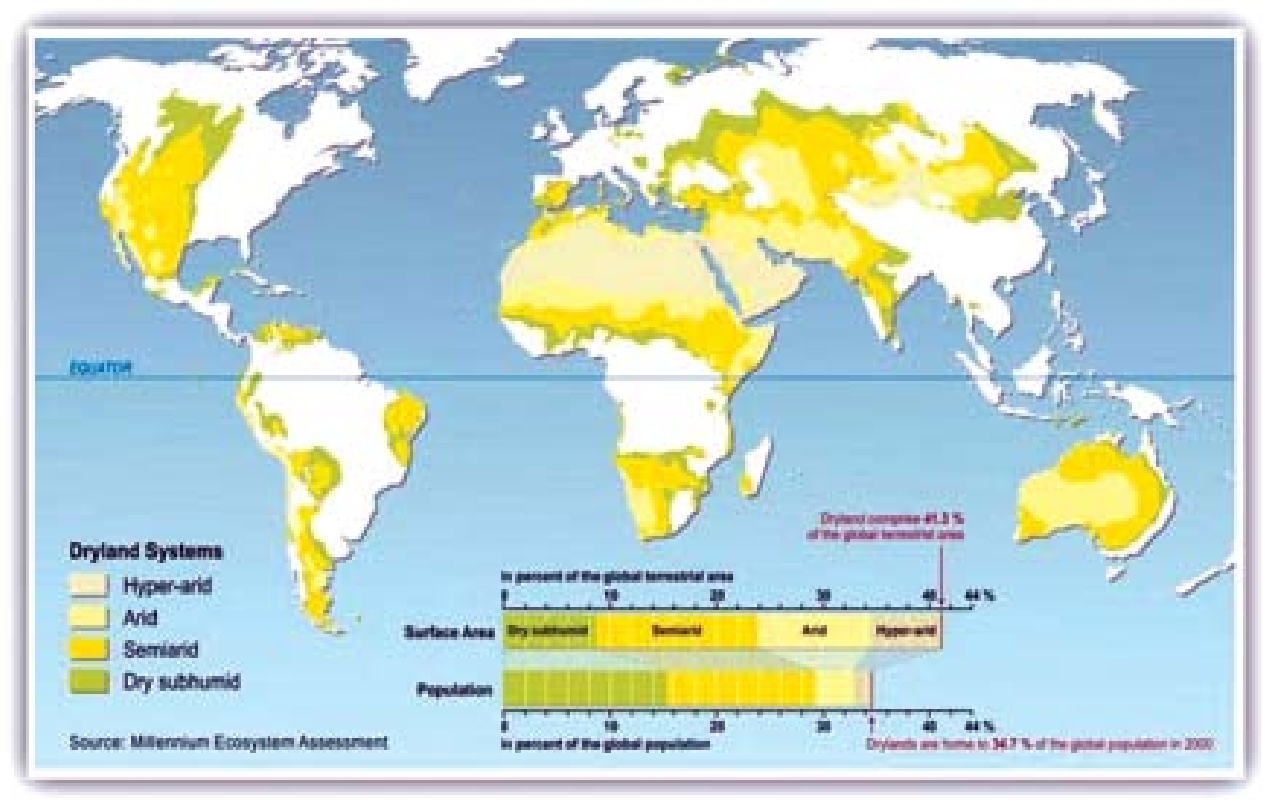

Figura 1. Tierras secas a nivel mundial

Fuente: PNUMA, 2006. Disponible en: http://www.greenfacts.org/es/glosario/tuv/tierras-secas.htm

minerales sin un manejo adecuado, poniendo en peligro la sostenibilidad de los ecosistemas y creando las condiciones propicias para el desarrollo de procesos de degradación de tierras, tales como la salinización, la erosión (pérdida de la capa vegetal que recubre el suelo), la compactación (por uso de maquinaria pesada) y, en general, la disminución y pérdida de toda forma de vida.

Además del aprovechamiento inadecuado por parte del hombre, los ecosistemas de ambientes secos están siendo afectados por el cambio climático global, causante de cambios bruscos de temperatura (alta o baja en zonas que antes no las reportaban), sequías e inundaciones con consecuencias ambientales impre-decibles. El cinturón desértico pericaribeño de Suramérica no es ajeno a dicha problemática ambiental. Hechos de trascendencia, como el inicio de la actividad petrolera durante la década de los treinta del siglo xx en el lago de Maracaibo; el auge del contrabando hacia el interior del continente a mediados del siglo $\mathrm{xx}$, con centros de acopio y de distribución en las ciudades de Maracaibo (Venezuela) y Maicao (Colombia), y la apertura en la década de los años ochenta de la explotación de la mina de carbón El Cerrejón para el comercio internacional, en las estribaciones de la serranía del Perijá, constituyen las principales fuerzas políticoeconómicas que han contribuido a los procesos de transformación y reconfiguración espacial de la península de la Guajira. 
La incorporación en el espacio geográfico de los nuevos elementos producto de las economías de mercado, de las políticas públicas y, en general, de las fuerzas naturales y sociales que operan sobre el territorio de la Guajira, están modificando las estructuras y dinámicas de funcionamiento espacial, creando desequilibrios territoriales que se hace necesario evaluar para poder formular e implementar acciones de planificación ajustadas ala realidad del medio natural y social.

\section{Metodología}

La presente investigación aborda el estudio del espacio geográfico del desierto de la Guajira bajo el enfoque conjunto de la Geografía Cultural y la Geografía Física, con el fin de indagar en una de las categorías de análisis de los estudios geográficos: la configuración y organización de los territorios. Corresponde a una investigación de tipo descriptivo-explicativo, por cuanto señala las características de los paisajes del desierto de la Guajira, cuyos mecanismos subyacentes de formación, funcionamiento y mantenimiento son estudiados como un sistema de interacciones (Bertalanffy, 1976, citado por Flórez y Thomas, 1993), a fin de lograr el análisis de la realidad con un doble carácter: sintético y analítico o global y especializado. El método de estudio utilizado es, en esencia, analíticosintético, en virtud de que se realiza el análisis individual de los elementos constitutivos del paisaje para posteriormente sintetizarlos mediante el examen de sus relaciones e interconexiones. En este sentido, la aproximación idiográfica-corológica de la región (Méndez y Molinero, 1998) adquiere trascendental importancia, por fundamentarse en el principio de que el espacio está dotado de una serie de propiedades específicas que es necesario conocer en detalle para valorar y actuar sobre él.

\section{El proceso de organización del espacio en la península de La Guajira}

La categoría de análisis del espacio geográfico referida a su organización constituye una de las aproximaciones que desde la ciencia geográfica se han construido con fines prácticos para la gestión de los territorios en sus diversos componentes (social, económico, político, cultural). El concepto de organización del espacio surge en los teóricos como una manera de entender la relación entre las personas, los objetos y la tierra, bajo una concepción funcionalista del espacio geográfico. El pionero en concebir este concepto fue el francés Jean Labasse (1973), quien en su obra La organización del espacio demostró que para realizar la ordenación de un territorio es necesario tener una visión sintética y locacional de él, es decir, un sentido de lo espacial, de la correlación de todos los hechos que se registran sobre un mismo territorio, que complete las visiones parciales (analíticas, sectoriales) de los científicos especialistas. 
Según Coraggio, se llega al concepto de organización espacial "cuando una configuración es sostenida por un proceso social que la refuerza y conserva o cuando es producto de actos voluntarios en función de ciertos objetivos conscientes" (1989). En este contexto, el espacio geográfico, como construcción social, es organizado por actores y agentes sociales, atendiendo a intencionalidades, valores e intereses múltiples, en el marco de las limitaciones que le imprimen las condiciones físico-naturales, las fuerzas materiales disponibles y el avance en ciencia y tecnología (Figura 2).

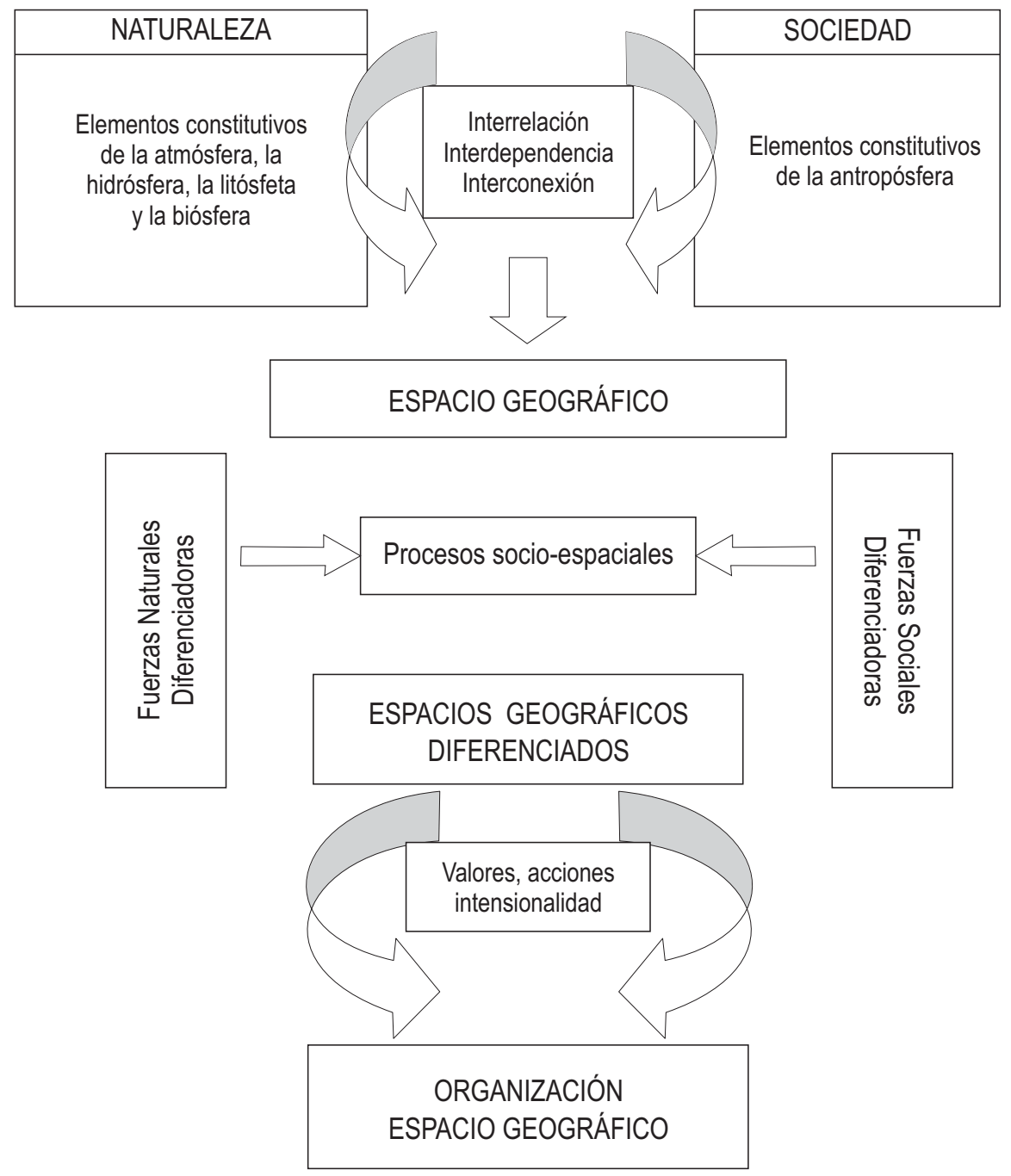

Figura 2. La organización del espacio geográfico

Fuente: elaboración propia a partir de Brunet y Dollfus (1990) y Santos (1996). 
Cada sociedad organiza su territorio según una espacialidad que le es propia y que depende de sus valores y de sus normas, así como también de la elección de sus actividades y de su dominio técnico, y se la analiza a partir de los principales componentes del funcionamiento de los territorios que son: la apropiación, el hábitat, la circulación, la explotación o producción, y la administración o gestión (Hypergéo, 2004).

\subsection{Estructuración del medio físico- biótico}

4.1.1 Geología y geomorfología. La posición geográfica de Colombia, en el extremo noroeste del continente suramericano, hace que la región natural del Caribe esté influenciada por la interacción de las placas tectónicas del Caribe y de Suramérica, y que las unidades geológicas aflorantes en el área presenten diferentes estilos estructurales relacionados con los eventos orogénicos que han afectado el territorio colombiano.

La evolución geológica de la región Caribe de Colombia está ligada, hasta finales del Cretácico y principios del Paleógeno (100 Ma.), a los eventos que moldearon el extremo norte de la cordillera de Los Andes. Debido al empuje ejercido por la placa del Caribe sobre el borde nororiental de la placa de Suramérica se inicia en el Eoceno la separación y rotación en sentido Este (entre $35^{\circ}$ y $45^{\circ}$ ) del bloque formado por la sierra nevada de Santa Marta y la península de la Guajira, y se origina el sistema de fallas de Oca y de Cuisa en dirección E-W, lo cual produce la deformación del bloque y el arqueamiento de las estructuras regionales, con la consecuente ampliación de la cuenca baja del río Magdalena y la flexión de la serranía del Perijá (Ingeominas, 2005).

Durante el Cuaternario tiene lugar la fase final de sedimentación de la cuenca, con predominio del ambiente fluvial sobre el marino, constituyendo amplias terrazas, abanicos y glacis moldeados por las condiciones áridas reinantes.

Las formas del relieve de la Alta Guajira son la resultante de la interacción de los distintos procesos que han actuado sobre los materiales litológicos a través del tiempo. Se presentan tres grupos de sistemas morfogenéticos ${ }^{3}$ : los del litoral, los de la depresión tectónica y los de la montaña baja (Figura 3).

4.1.2 Clima y vegetación. Estudios paleobotánicos realizados en el cinturón desértico pericaribeño, fechados en más de 14.000 años, revelan un acentuado neoendemismo de parte de varios elementos típicos de la flora actual, así como un discreto número de espinas afines a Prosopis (trupillo), Caesalpinia (dividivi) y Cercidium. Las extensas salinas y sebkhas intralitorales presentes constituyen testimonios sedimentológicos del ambiente árido predominante más allá

3 Un sistema morfogenético es entendido como "el conjunto de procesos interdependientes que generan un modelado específico en un espacio determinado" (Tricart, 1977; citado por Flórez, 2003). 


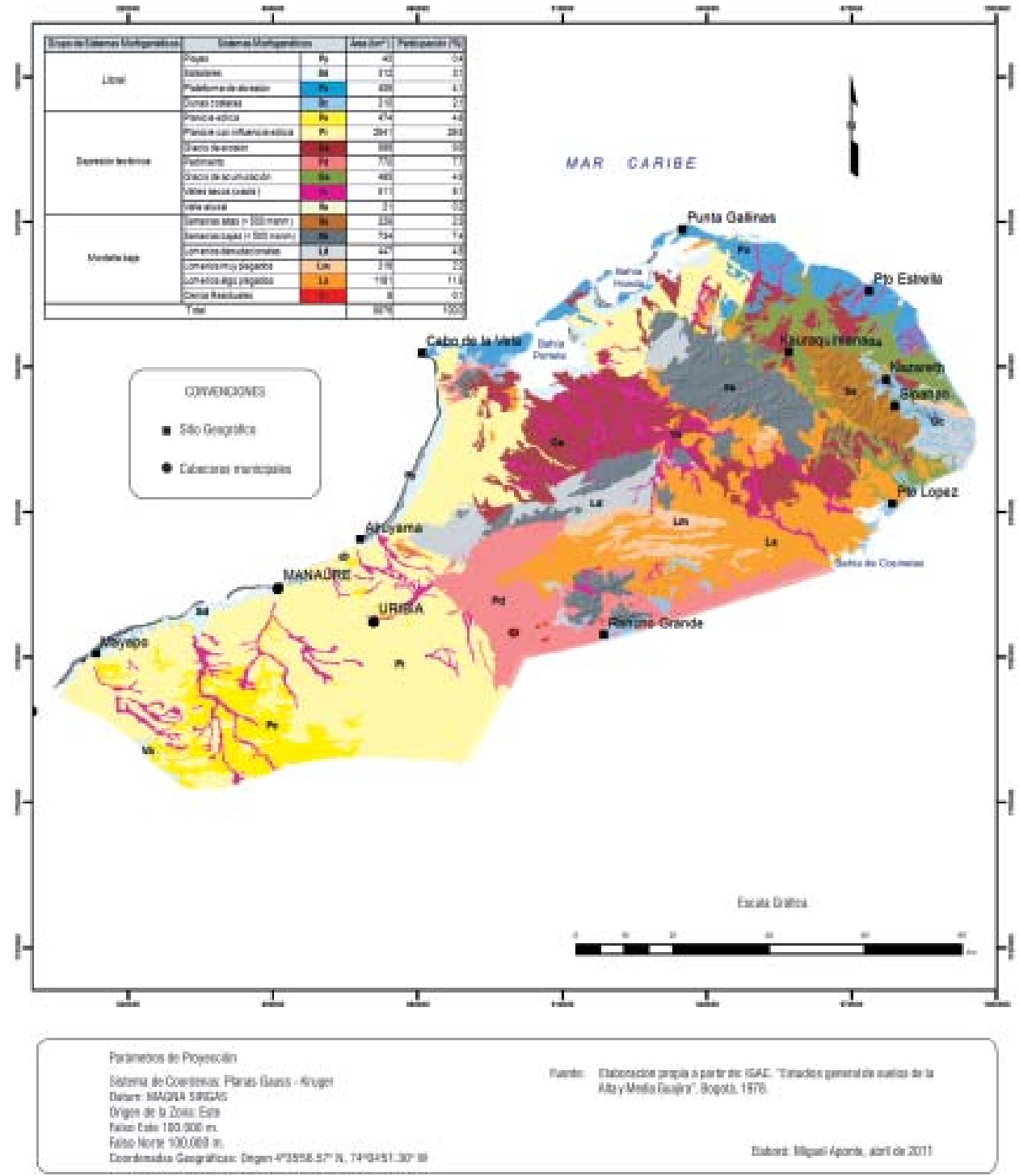

Figura 3. Sistemas morfogenéticos

de la última glaciación, es decir, a lo largo de todo el Holoceno (Ochsenius, 1981).

El clima actual de la península de la Guajira se caracteriza por presentar escasas lluvias (distribuidas en los dos semestres del año), insolaciones fuertes, vientos constantes y alta evaporación. Su temperatura promedio está entre los $27{ }^{\circ} \mathrm{C}$ y los $29^{\circ} \mathrm{C}$, varía poco durante el año y no se ve afectada por la altura, pues no se encuentran elevaciones de consideración. 
De la relación entre los valores de precipitación media anual y los equivalentes a la evapotranspiración potencial se calculan los grados de aridez de un territorio (Eslava, 1993), que son utilizados por el Programa de las Naciones Unidas para el Medio Ambiente (PNUMA) para clasificar los desiertos del mundo. Los resultados indican que la región de la Alta Guajira pertenece a la categoría de tierras áridas y semiáridas, dentro del sistema de clasificación mundial de desiertos (índices de aridez mayores a 0,03 y menores a 0,50 ) (Figura 4).

El ecosistema desértico de la Alta Guajira se caracteriza por tener una cobertura vegetal de porte bajo, con presencia de arbustales (plantas leñosas perennes con altura entre 0,5 y $5 \mathrm{~m}$ ) y herbazales (plantas sin estructura de tallo definida, con especies de altura inferior a $2 \mathrm{~m}$ )

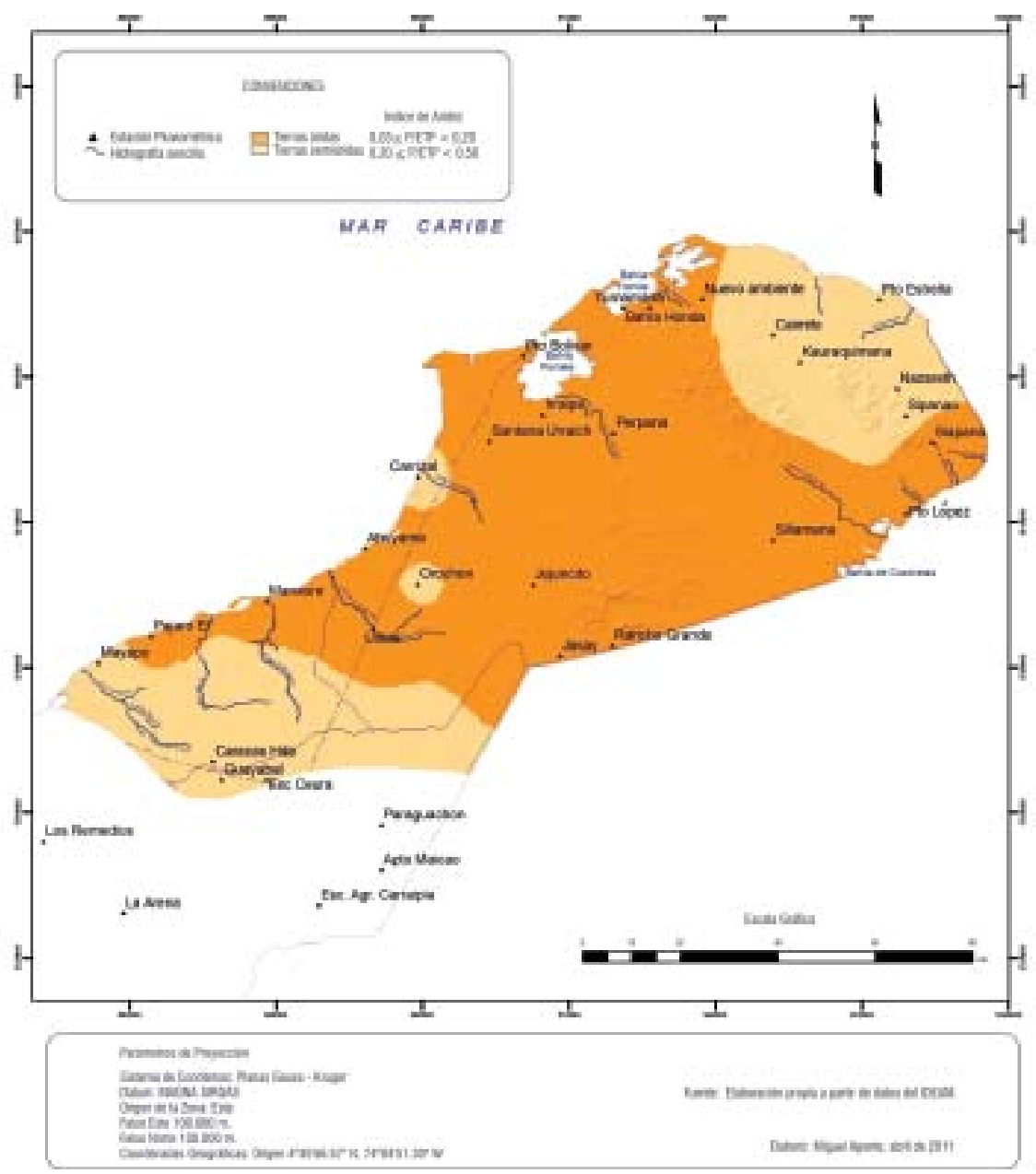

Figura 4. Índice de aridez 
densos o abiertos. Las plantas, en su mayoría, son heliófilas, con hojas pequeñas, coriáceas y espinosas. Algunas especies arbustivas (espinares y cardonales) tienen la clara propiedad de ser phreatófitas, es decir, capaces de sobrevivir durante algún tiempo sin lluvias, valiéndose únicamente de la captación de agua o humedad subterránea (freática).

De acuerdo con el mapa general de ecosistemas producido por IDEAM et al. (2007), en la península de la Guajira se presentan dos grandes biomas ${ }^{4}$ : el Desierto tropical, perteneciente a la provincia de humedad árida, y el Bosque seco tropical, con características de humedad de tipo muy seco.

\subsection{Estructuración socio-cultural}

A la llegada de los conquistadores españoles a la península de la Guajira y zonas aledañas, estos territorios estaban habitados por varios grupos indígenas, como los caquetíos, makuiras, cocinas, guanebucanes y paraujanos, entre otros. Los indios cocinas habitaban la parte central de la península y eran principalmente recolectores y cazadores, en tanto que el resto de los grupos practicaban la horticultura como principal fuente de sustento (Rivera, 1990). Estas comunidades indígenas pertenecían a la familia lingüística Arawak, y se cree que procedían de las tierras bajas de las hoyas hidrográficas del Amazonas y del Orinoco.

\subsubsection{El poblamiento de la península de} la Guajira durante la Colonia. La península de la Guajira, por su ubicación geoestratégica en el extremo septentrional de Sudamérica, y por disponer de un buen número de accidentes geográficos costeros de importancia marítima, constituyó una de las puertas de entrada utilizadas por los conquistadores europeos a finales del siglo $\mathrm{XV}$, en su cometido de expandir su poder económico, militar y territorial a través de la invasión de los territorios de ultramar. Sin embargo, los conquistadores españoles se encontraron con un territorio hostil, tanto por las condiciones del medio natural, estacionalmente deficitario en agua dulce, como por el estilo de vida de los nativos, fundamentado en "la polirresidencialidad" y dedicados a la caza, la recolección y la horticultura" (Instituto Colombiano de Cultura Hispánica, s. f.).

El modelo de poblamiento hispánico estaba conformado por una estricta jerarquía de ciudades, villas, parroquias y pueblos de indios ${ }^{6}$, cada uno de ellos

4 Los biomas suelen considerarse como el conjunto de ecosistemas terrestres afines por sus rasgos estructurales y funcionales, y diferenciables por sus características vegetales (Hernández y Sánchez, 1992).

5 La polirresidencialidad supone el mantenimiento de varias viviendas en la península, casi siempre en función de apoyos comerciales y de optimizar el uso de servicios médicos y escolares según la oferta diferencial o las ventajas comparativas entre Colombia y Venezuela (Biblioteca Luis Ángel Arango, 2009).

6 Se entiende por pueblos de indios las congregaciones de aborígenes en un determinado espacio, impulsadas por las autoridades españolas para representarles e inculcarles un orden social y unas creencias cosmológicas. Este ordenamiento espacial se constituye en un sistema de significados a través de los cuales se comunica, experimenta, explora y reproduce un sistema social, en este caso el hispano (Polo, 2005). 
con funciones determinadas y normalizadas (Corpes, 1993: 36). Fue así como empezaron por fundar la ciudad de Santa Cruz, levantada en la costa nororiental por Alonso de Ojeda en 1502 y echada a perder un año después por las disputas internas entre sus moradores y los nativos (Instituto Colombiano de Cultura Hispánica).

Una de las estrategias utilizadas por la Corona española para el sometimiento, control y sujeción de los aborígenes de la Guajira consistió en la implementación de las misiones religiosas capuchinas, durante la primera mitad del siglo XVIII, cuya actividad sentó las bases para conformar la red espacial de pueblos de indios que caracterizó este territorio durante esta centuria. El proceso lo iniciaron los misioneros capuchinos, en 1716, con la congregación de indios y la fundación del pueblo de San Nicolás de los Menores, distante pocas leguas al este de Riohacha. Hacia el año de 1724 se fundaron los pueblos de La Cruz, San Antonio de Orino, San Juan del Rincón, San Pedro Nolasco de Salado, Nuestra Señora de la Merced de Calabozo y San Ramón de Parauje, este último cerca de la actual línea fronteriza con Venezuela.

La característica dispersión espacial de los indios guajiros, quienes no estaban acostumbrados a vivir en congregaciones, hizo que esta primera labor de evangelización fracasara y que algunos pueblos desaparecieran, pues los indios preferían "retirarse al monte antes que escuchar el catecismo" (Polo, 2005). Para antes de 1760 se habían fundado cuatro pueblos más en la parte oriental de la península: Macuira, Bahía Honda, Sabana del Valle y Chimare, y otros tantos como parte de la estrategia de pacificación que la Corona española contrató con el asentista de negocios y víveres Bernardo Ruiz de Noriega: Sabanas de Ypapa, Bahía Honda y Carrizal.

En el año 1769, los indios guajiros se alzaron en armas ante el inconformismo generalizado provocado por la dominación y el nuevo orden imperante. Producto de las batallas libradas fue la destrucción de la mayoría de pueblos fundados hasta ese entonces. Este hecho motivó a los españoles a incrementar sus acciones militares. Fue así como el ingeniero Antonio de Arévalo, asignado por la Corona para someter a los sublevados, decidió construir entre 1772 y 1774 cuatro poblaciones fortificadas: San José de Bahía Honda, Apiesi, San Bartolomé de Sinamaica y la villa de San Carlos de Pedraza.

Finalizando el siglo XVIII, en la región solamente quedaban erigidas las ciudades de Riohacha y Maracaibo, pertenecientes a las gobernaciones del Río de La Hacha y de Venezuela, respectivamente, así como también los siguientes pueblos reconstruidos hacia 1771: Camarones, La Cruz, Orino, El Toco (Rincón de Cayus), El Rincón, Boronata, Carrizal y San Juan Bautista de Bahía Hondita (Figura 5).

El periodo de conquista española en la península de la Guajira no tiene afinidad con lo sucedido en otras regiones del país, puesto que la 


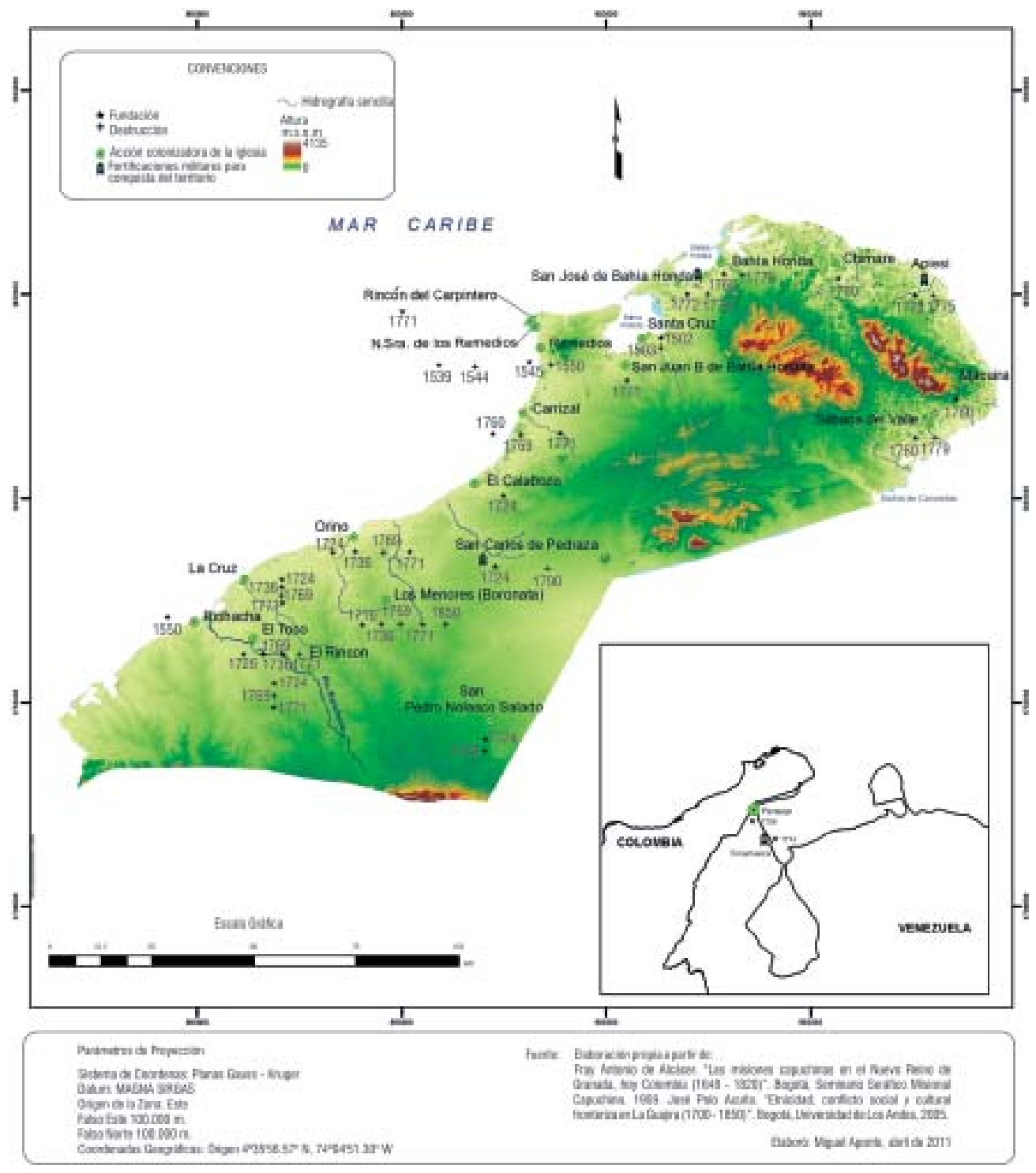

Figura 5. Pueblos de indios y fundaciones hispánicas. Siglos XVI al XVIII

resistencia indígena wayúu frente al sometimiento y acatamiento a las "autoridades reales" se extendió hasta el siglo XVIII, y aun por varias décadas más, como se verá en el siguiente aparte.
4.2.2 El poblamiento de la península de la Guajira durante la República. El fracaso de la campaña militar española permitió el florecimiento del contrabando durante las dos últimas décadas del siglo XVIII y la 
primera del siglo XIX. Desde el auge de las plantaciones de caña de azúcar en Jamaica y Haití, a comienzos del siglo xvIII, los riohacheros y también los guajiros habían empezado a vender clandestinamente ganado a los extranjeros para llevar a esas islas, y aun cuando el gobierno español no aprobaba este contrabando, lo toleró porque no era amenaza real contra su dominio legal sobre esta región.

A partir de 1750 los riohacheros empezaron a cortar palo de tinte, procedente de las estribaciones de la Sierra Nevada y de Valledupar, para venderlo a los holandeses y a los ingleses en las costas y bahías desiertas de la Guajira (De la Pedraja, 1988). A cambio, los riohacheros recibían de los ingleses, principalmente, telas y también algo de aguardiente y otros objetos; los guajiros, por su parte, recibían en pago por su ganado aguardientes, armas, algunos implementos y ropas.

El decreto expedido el 13 de diciembre de 1833 ordenaba reducir los indígenas, que en su mayoría todavía eran errantes, a pueblos fijos cuya construcción estaría financiada por el gobierno. Esta estrategia del gobierno republicano también fracasó, ya que los indios guajiros rehusaban la religión católica, en buena parte porque no se les catequizaba en su propio idioma. La ley de 1843 prohibió a los extranjeros arribar a las costas de la Guajira y, en adelante, ellos tendrían que dejar sus cargamentos en Riohacha, pagando los derechos de aduana usuales.

Hacia 1846, la parte norte de la Guajira quedó constituida jurídicamente como
"Territorio Nacional”, entidad políticoadministrativa que pretendía, bajo un régimen especial, crear los mecanismos para que los indios guajiros se pudieran incorporar más fácilmente a la "vida civilizada" (De la Pedraja, 1988). Una vez creado el "territorio guajiro", el gobierno decidió enviar nuevamente misioneros, como la manera más apropiada de atraer los indígenas a la vida civilizada; sin embargo, esta medida también fracasó, ante el abandono en dos ocasiones (1873, 1880) de la misión evangelizadora de Marauyén, establecida a las afueras de Riohacha en los años 1846 y 1879. Ante el nuevo fracaso de las misiones, el gobierno republicano decidió ensayar una combinación de colonos, soldados y misioneros, y auspició la fundación de Camarones, Dibulla, El Paso y Soldado; de estos poblados solo se establecieron los dos primeros, en buena parte porque estaban localizados en una zona de donde pronto serían expulsados los guajiros. El Paso desapareció en la década de los cincuenta del siglo XIX, junto con Menores y Moreno (Figura 6).

A principios del siglo $\mathrm{xx}$, inspirados en el discurso civilizador de las élites y en el ambiente sociocultural de los años veinte, en relación con los indígenas del país, los capuchinos fundan los orfelinatos para niños wayúu, como una "obra de la civilización”.

El recuento somero de los anteriores apartes permite comprender dos de las características que constituyen la identidad cultural de los indios wayúu: su forma de habitar el espacio, de manera 


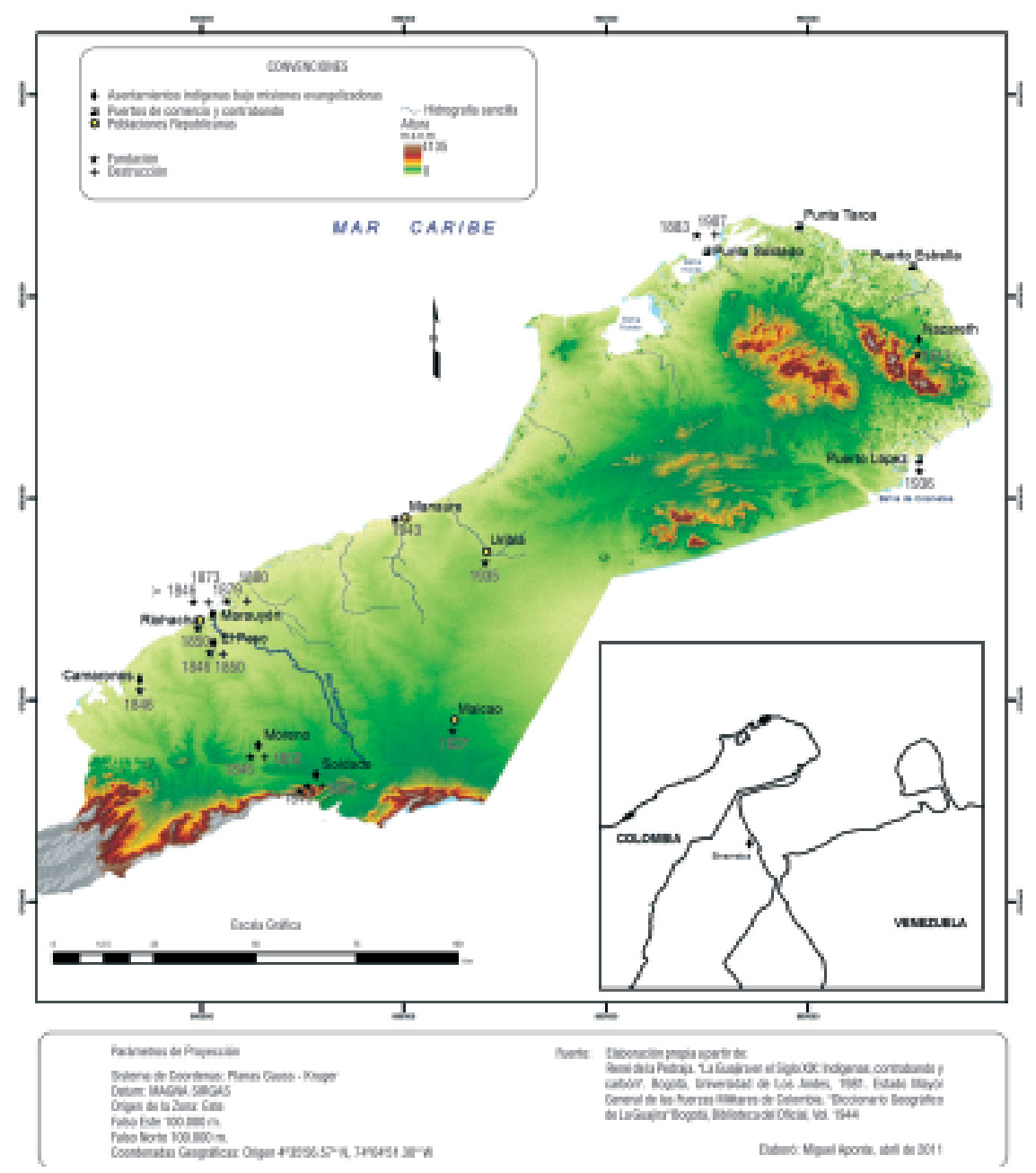

Figura 6. Ciudades, pueblos de indios y puertos comerciales. Siglos XIX y xX

dispersa, y su autonomía de poder, con claros matices de descentralización política; ambas de importancia relevante al momento de analizar la manera peculiar como se ha configurado este territorio a través de la historia.

A comienzos del siglo $\mathrm{xx}$ se inicia el proceso de creación de pueblos, como resultado de la pacificación de los territorios producto de la presencia política, económica y social de los Estados de Colombia y Venezuela y de la histórica paz firmada entre las fuerzas militares de ambos países luego de la batalla de Guaraguarao, en el año de 1901 (Estado Mayor General, 1944: 84, 121). 


\subsection{Síntesis territorial wayúu}

La región geográfica de la Alta Guajira presenta una organización espacial singular y única, soportada por estructuras territoriales básicas resultantes de la interacción de factores internos y externos, y del desarrollo de procesos socio- espaciales que han revestido este territorio de una cohesión y una funcionalidad específica. Las siguientes son las características sobresalientes de dicha organización, establecidas mediante coremas, como elementos útiles para la representación espacial de los fenómenos geográficos (Figura 7).

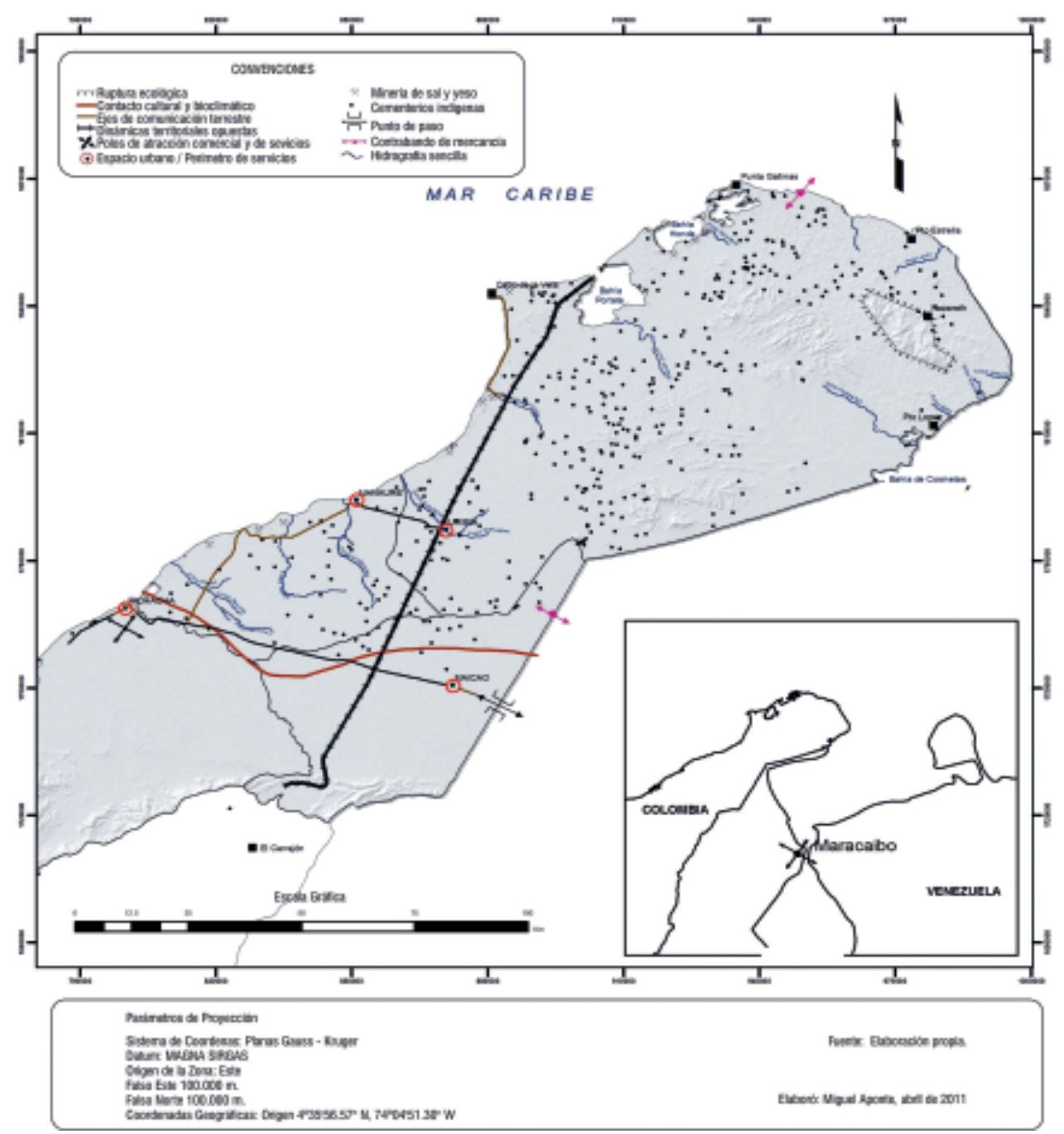

Figura 7. Organización del territorio 
Contacto cultural y bioclimático: la zona semidesértica de la Alta Guajira presenta unas características particulares que la diferencian de los territorios aledaños: se encuentra habitada por la etnia wayúu, que dispone de una organización social y política propia. Las tierras pertenecen a toda la comunidad y se agrupan bajo la denominación de resguardo indígena. Corresponde al área más seca del país.

Ruptura ecológica: no toda la Alta Guajira tiene características áridas. La serranía de Makuira marca un contraste abrupto respecto a los ecosistemas predominantes en la zona y constituye un referente simbólico con alto valor cultural.

Espacio urbano/perímetro de servicios: el territorio wayúu no dispone de servicios públicos básicos; solamente las cabeceras municipales de Riohacha, Maicao, Manaure y Uribia, así como los poblados menores del Cabo de la Vela y Nazareth, cuentan con oferta de agua potable, alcantarillado y energía eléctrica.

Dinámicas territoriales opuestas: están dadas por la inclusión en el territorio wayúu de la vía férrea que transporta el carbón mineral desde la mina de El Cerrejón, en las estribaciones de la serranía de Perijá, hasta el sitio de embarque en Puerto Bolívar.

Patrón disperso de distribución de la población: es una característica general de las zonas áridas y desérticas del mundo. En la Alta Guajira, las viviendas de los wayúu están asociadas a una fuente de agua (jagüey, casimba o pozo), a un cementerio familiar y a una huerta de cultivos de pancoger. La densidad población en la zona rural oscila alrededor de $15 \mathrm{hab} / \mathrm{km}^{2}$.

Puntos de entrada y salida de mercancías: por la posición geoestratégica de la península de la Guajira y como una forma de comercialización heredada del pasado, aún hoy se presentan sitios clandestinos por donde ingresan al país diversos tipos de mercancías de contrabando; en el mapa se señalan cerca de Taroa y al norte de Maicao, pero su ubicación es muy dinámica, por la misma connotación de aleatoriedad que presenta esta forma de comercio. Paraguachón es un sitio de paso obligado de personas y mercancías, que conecta en la Alta Guajira los estados de Colombia y Venezuela.

Polos de atracción comercial y de servicios: corresponden a las ciudades de Riohacha, en Colombia, y de Maracaibo, en Venezuela, que ofrecen diversos tipos de servicios y hacia donde se dirigen las personas en busca de mejorar sus condiciones de vida.

Ejes de comunicación terrestre: se señalan en el mapa las vías terrestres transitables en cualquier época del año y que conectan las ciudades de Riohacha, Maicao, Manaure, Uribia y 
el sitio turístico del Cabo de la Vela. A partir de Riohacha y de Maicao, el territorio wayúu se conecta con el resto del país.

Minería de sal y de yeso: se señalan en el mapa los principales sitios de explotación de sal y yeso con fines de comercialización, aunque este último ya casi no se explota.

\section{Conclusiones}

El modelo de organización del espacio geográfico de la Alta Guajira tiene como eje central la espacialidad wayúu, materializada a través de las prácticas sociales de la comunidad wayúu y que tiene como fundamento su propia cosmovisión, en la que el equilibrio de la vida adquiere trascendental importancia. La práctica de la trashumancia ejercida por los wayúu, según la temporada de lluvias en el territorio, contribuye a la recuperación natural de los ecosistemas utilizados y a disminuir los procesos de desertización de las tierras.

La forma de explotación tradicional indígena wayúu, caracterizada por la obtención de productos según las posibilidades que ofrece el medio natural y sin fines de generación de excedentes con destino a la comercialización, constituye uno de los factores ambientales determinantes en la preservación del territorio de la Alta Guajira. Cambios en los sistemas de producción hacia economías capitalistas podrían impactar desfavorablemente la estructura sociocultural y natural del territorio.

En el mundo occidental se ha construido la idea de que el desarrollo de un territorio cualquiera conlleva implícito una serie de elementos, muchos de ellos encaminados a satisfacer las necesidades de las poblaciones humanas asentadas en las zonas urbanas. Para el caso wayúu esta noción de desarrollo no tiene cabida, debido a que con su estilo de vida particular, de gran adaptación y respeto hacia la naturaleza, han habitado este territorio desde tiempos inmemoriales y han desarrollado una cultura propia que requiere ser conservada.

Al considerar que la desertización de las tierras es inducida por el manejo inadecuado de los recursos naturales por el ser humano, no se puede afirmar que en la Alta Guajira se presenten procesos de desertización en razón a que: a) el modo de producción corresponde al «tradicional indígena», caracterizado por la extracción de productos de manera mesurada y según la oferta ecosistémica de la zona; b) la baja densidad poblacional $\left(15 \mathrm{hab} / \mathrm{km}^{2}\right)$, que ejerce impactos ligeros sobre el medio natural, y c) las características propias de los suelos en relación con contenidos de sales, sodio y carbonatos de calcio, que son inherentes al desarrollo evolutivo natural de ellos, productode la influencia marina geohistórica de la península de la Guajira. 
En las zonas desérticas del mundo tienen lugar diversas culturas que, con sus estilos de vida propios, generan unas estructuras espaciales y una funcionalidad específica de cada espacio geográfico. Así se ha comprobado con el estudio de caso del sector que tradicionalmente se conoce como "desierto guajiro", soportado por una estructura socio-cultural sólida, construida a través de la historia de la humanidad y por unas estructuras naturales particulares. Para los fines de planificación y de ordenamiento territorial, estos espacios geográficos de características singulares y personalidad propia deben ser analizados con una visión integral que incluya tanto a los expertos en las ciencias naturales como a los expertos en las ciencias económicas, políticas, sociales y culturales.

Por corresponder este espacio geográfico a un territorio cultural único e irrepetible, es necesario que las propuestas para su desarrollo se dirijan hacia lo "local", con una amplia y activa participación de la población nativa en la construcción del territorio soñado o pensado a través de los proyectos de vida por parte de los distintos clanes que conforman el pueblo wayúu, en pro de la conservación cultural y natural del territorio.

\section{Literatura citada}

Brunet, R. y Dollfus, O. (1990). "Estructuras y dinámica del espacio". En: Mondes nouveaux, Geographie Universelle. París: Hachette Reclus. Capítulo traducido en 1998 por: Flórez, A.; Montoya, J.; Delgado, O. (Eds). Lecturas en Geografía - Traducciones (pp. 92-140). Bogotá: Universidad Nacional de Colombia.

Consejo Regional de Planificación de la Costa Atlántica. (1993). Mapa Cultural del Caribe Colombiano. Santa Marta: CORPES Costa Atlántica.

CCC. Convención de las Naciones Unidas sobre Cambio Climático. (1997). Convenio Marco de las Naciones Unidas sobre el Cambio Climático.

Coraggio, J. L. (1989). "Sobre la espacialidad social y el concepto de región". En: International Institute for Environmental Development - América Latina (IIEDL). La cuestión regional en América Latina (pp. 67-105). Quito: Ediciones CIUDAD.

De la Pedraja, R. (1988). "La Guajira en el siglo xix: Indígenas, contrabando y carbón”. En: El Caribe colombiano. Selección de textos históricos (pp. 1-38). Barranquilla: Ediciones Uninorte. 
Eslava, J. (1993). "Climatología y diversidad climática de Colombia". Revista de la Academia Colombiana de Ciencias Exactas, Físicas y Naturales, 18 (71): 507538.

Estado Mayor General de las Fuerzas Militares de Colombia. (1944). Diccionario Geográfico de la Guajira. Bogotá: Biblioteca del Oficial. Vol. 19.

Flórez, A. y Thomas, J. (1993). "La teoría general de sistemas". Cuadernos de Geografía, IV (1-2):111-137). Bogotá: Universidad Nacional de Colombia.

Flórez, A. (2003). Colombia: evolución de sus relieves y modelados. Bogotá: Universidad Nacional de Colombia, Unibiblos.

Hernández, J. y Sánchez, H. (1992). "Biomas terrestres de Colombia”. En: Halffter, G. La Diversidad Biológica de Iberoamérica (pp. 136-152). I. Xalapa: Instituto de Ecología A.C.

Hypergéo. (2004). Conceptos, teorías y fundamentos epistemológicos en Geografía. Obtenido el 12 de enero de 2010 desde http://www.hypergeo.eu/spip.php?rubrique50.

Instituto Colombiano de Cultura Hispánica. s. f. "Los wayúu”. En: Geografía Humana de Colombia. Nordeste indígena. Tomo II. Publicación digital en la página web de la Biblioteca Luis Ángel Arango del Banco de la República. Obtenido el 3 de agosto de 2009 desde http://www.lablaa.org/blaavirtual/geografia/geograf2/ wayuu21.htm\#WAYUU

Instituto de Investigación e Información Geocientífica, Minero Ambiental y Nuclear. (2005). Evolución tectónica de la región Caribe de Colombia. Bogotá: Ingeominas.

Instituto de Hidrología, Meteorología y Estudios Ambientales et al. (2007). Ecosistemas continentales, costeros y marinos de Colombia. Bogotá: IDEAM.

Instituto Mundial sobre Recursos. (2005). Ecosystems and Human Well-being: Desertification Synthesis. Evaluación de los Ecosistemas del Milenio. Washington D. F. WRI, Island Press.

Labasse, J. (1973). La organización del espacio. Madrid: Instituto de Estudios de Administración Local.

Méndez, R. y Molinero, F. (1998). "Los factores de organización territorial a escala planetaria y la división regional del mundo". En: Espacios y Sociedades. Introducción a la geografía regional del mundo (pp. 17-31). Barcelona: Ariel.

Ochsenius, C. (1981). "Ecología del pleistoceno tardío en el cinturón árido pericaribeño". Revista CIAF, 6 (1-3): 365-372. Bogotá: Centro Interamericano de Fotointerpretación.

Perspect. geogr. Vol. 15. Año 2010, pp. 157-176 175 
Polo, J. (2005). Etnicidad, conflicto social y cultura fronteriza en la Guajira (1700-1850). Bogotá: Universidad de los Andes, Centro de Estudios Socioculturales e Internacionales -CESO-.

PNUMA. Programa de las Naciones Unidas para el Medio Ambiente. (2006). Global Deserts Outlook. San Diego: Exequiel Ezcurra, Natural History Museum.

Rivera, A. (1990). "La metáfora de la carne sobre los wayúu en la península de la Guajira”. Revista Colombiana de Antropología. 28:87-136. Bogotá: Colcultura.

Santos, M. (1996). Metamorfosis del espacio habitado. Barcelona: Oikos-Tau. 